\title{
GESTÃO AMBIENTAL E POLÍTICAS PÚBLICAS ANÁLISE DA IMPLEMENTAÇÃO DO CADASTRO AMBIENTAL RURAL (CAR) NO DISTRITO FEDERAL
}

Renata Nogueira Dias dos Santos (AUTOR PRINCIPAL) - renata.nogueira.ambiental@ gmail.com Universidade Católica de Brasília - UCB

Tatyane Souza Nunes Rodrigues - tatyane@ucb.br

Universidade Católica de Brasília - UCB

Janaína Juliana Maria Carneiro Silva - jajumaca@ gmail.com Instituto Brasileiro de Meio Ambiente e Recursos Renováveis - IBAMA

Resumo: A conservação e manutenção dos recursos naturais são de extrema importância, e impõe um desafio de regularização das propriedades rurais. Com o Novo Código Florestal que dispõe sobre a proteção da vegetação nativa, foi criado um instrumento de monitoramento das propriedades rurais, o Cadastro Ambiental Rural (CAR). O CAR é um registro público eletrônico de âmbito nacional, sendo obrigatório para todas as propriedades e posses rurais. $\mathrm{O}$ presente trabalho tem como objetivo geral analisar a implementação do CAR no âmbito do Distrito Federal (DF), no período de 2012 à 02 de Maio de 2015. No que tange às legislações vigentes relacionadas ao CAR, observa-se a publicação de diferentes requisitos para o preenchimento de lacunas existentes e aperfeiçoamento deste instrumento. Foi levantado o quantitativo de propriedades já cadastradas no âmbito do DF até 5 de Maio de 2015, sendo o valor encontrado inferior, quando comparado com o montante total das propriedades. Tem-se como sugestões um investimento para melhor divulgação da ferramenta, adaptação da plataforma e capacitação dos funcionários e proprietários. Dentre os obstáculos diagnosticados na implementação da ferramenta, nota-se que a resolução disponível na plataforma do Sistema de Cadastro Ambiental Rural (SICAR) é insuficiente para atender as pequenas propriedades no DF. Constatou-se também que a plataforma não contempla as áreas legalmente protegidas que são peculiares à região, como campo de murundu e canal natural de escoamento superficial.

Palavras-chave: Sistema de Cadastro Ambiental Rural. SICAR. Imóvel Rural.

\section{INTRODUÇÃO E OBJETIVOS}

O Brasil é um país que apresenta um dos maiores índices de diversidade biológica do mundo, pois abriga pelo menos $20 \%$ das espécies do planeta. Isso implica em uma maior responsabilidade no que diz respeito à conservação dos recursos naturais (SILVA et al., 2011).

A conservação e a manutenção desses recursos possibilitam que os serviços ambientais prestados pela natureza como a ciclagem de nutrientes, a proteção das bacias hidrográficas, o sequestro de carbono, amenização dos fenômenos violentos do clima, geração de solos férteis, controle de erosões, disponibilidade e qualidade da água continuem ocorrendo de forma equilibrada (EMBRAPA, 2014; IPAM, 2014). 

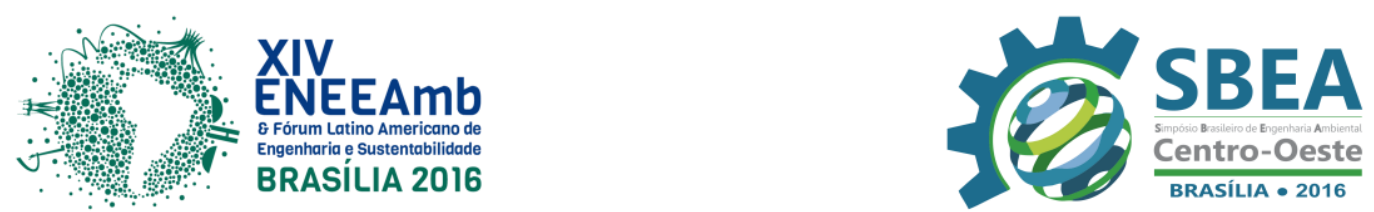

Neste contexto de grande riqueza está o Distrito Federal (DF), localizado integralmente no bioma Cerrado, que é o segundo maior bioma brasileiro, ocupando aproximadamente $21 \%$ do território nacional. O clima dessa região é marcado em dois períodos que são o chuvoso, que dura de outubro a março, e é seguido por um período seco, de abril a setembro. Considerado como um hotspot mundial de biodiversidade, o Cerrado apresenta extrema diversidade de espécies, mas partes dessas espécies estão ameaçadas de extinção em função da grande expansão da agricultura e intensa exploração local de produtos nativos (KLINK e MACHADO 2005).

O conceito de hotspots veio para auxiliar os conservacionistas a identificar as áreas mais importantes para a preservação das espécies e fornecer a base científica ao direcionamento de pesquisas e estratégias de conservação. Os hotspots são regiões que abrigam uma imensa diversidade de espécies endêmicas significativamente afetadas e alteradas pelas atividades humanas, tal conceito apresenta informações fundamentais para a proteção dessas regiões (GALINDO-LEAL 2005).

$\mathrm{O}$ uso prioritariamente agropecuário das áreas do cerrado geraram benefícios socioeconômicos inegáveis como o aumento da oferta dos produtos agrícolas tanto para uso doméstico como para exportação, ganhos na produtividade da agricultura, diversificação das economias locais e aumento da renda de municípios, e melhorias sociais em várias localidades (KLINK e MACHADO, 2005).

Tal fato impõe um desafio de regulação sobre as propriedades rurais, a fim de que possam produzir e cumprir o desafio da conservação, principalmente nas áreas consideradas especialmente protegidas por Lei.

A partir da Lei 12.651/12, conhecida como Novo Código Florestal, que dispõe sobre a proteção da vegetação nativa, foi criado um instrumento de monitoramento das propriedades rurais no país, o Cadastro Ambiental Rural (CAR).

A referida Lei apresenta o capítulo VI dedicado a tal instrumento, no âmbito do Sistema Nacional de Informação sobre o Meio Ambiente - SINIMA, o CAR é um registro público eletrônico de âmbito nacional, sendo obrigatório para todas as propriedades e posses rurais, devendo sua inscrição ser realizada no órgão ambiental municipal ou estadual. Ressalta-se que o mesmo capítulo dispõe sobre o que será exigido, minimamente, do proprietário ou possuidor rural para realizar a inscrição no CAR.

Em 2012 o CAR se torna obrigatório, por força da Lei 12.651/2012 regulamentada pelo Decreto 7.830/2012. Em 2014 o Decreto 8.235/2014 estabelece normas aos Programas de Regularização Ambiental (PRA) e a Instrução Normativa do MMA no 02/2014 estabelece os procedimentos gerais do Cadastro Ambiental Rural.

Assim, com a publicação do Código Florestal, seguida pelos Decretos $\mathrm{n}^{\circ}$ 7.830/2012, $\mathrm{n}^{\circ} 8.235 / 2014$ e da Instrução Normativa MMA n $\mathrm{n}^{\circ}$ 02/2014, foi estabelecido o CAR em nível nacional, com a finalidade de integrar as informações ambientais das propriedades e posses rurais, compondo base de dados para controle, monitoramento, planejamento ambiental e econômico e combate ao desmatamento.

Observa-se que o devido monitoramento das propriedades pelo CAR facilitará o monitoramento do cumprimento das restrições de uso das propriedades rurais no Brasil, tais como as Reservas Legais, Áreas de Preservação Permanente, Unidades de Conservação, entre outras áreas especialmente protegidas por Lei.

O Sistema de Cadastro Ambiental Rural (SICAR) apresenta módulo para inscrição no Cadastro Ambiental Rural, que está disponível em um site especifico no qual é possível fazer o cadastro, a consulta e o acompanhamento da situação de regularização ambiental dos imóveis rurais. Sendo que pode haver especificidades em cada Estado na 

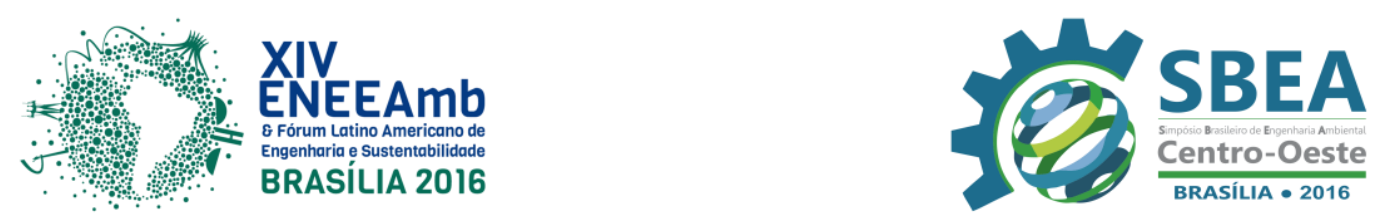

escolha da plataforma, pois pode adequar a plataforma para necessidades cabíveis de cada região (CAPCAR, 2014). Porém, o Distrito Federal optou pela ferramenta nacional que é o SICAR.

O SICAR é composto por módulos, sendo um de cadastro, outro receptor nacional e de analise. O cadastro de um imóvel rural no SICAR possui duas etapas distintas: o preenchimento das informações no Módulo de Cadastro e o envio da declaração para o Módulo Receptor. E tendo também a previsão do Módulo de Analise que os órgãos ambientais competentes iniciarão a análise dos respectivos cadastros (CAPCAR, 2014).

Assim, o presente trabalho tem como objetivo geral analisar a implementação do Cadastro Ambiental Rural (CAR) no âmbito do Distrito Federal (DF), no período de 2012 até 5 de maio de 2015. Ademais, tem como objetivos específicos: (a) Levantar o quantitativo de propriedades rurais cadastradas no CAR até 5 de Maio de 2015 e (b) Diagnosticar os obstáculos do DF na implementação da ferramenta.

\section{METODOLOGIA}

O presente estudo foi realizado por consultas às legislações vigentes em âmbito Federal e Distrital que englobam o assunto do Cadastro Ambiental Rural, abordando a importância deste instrumento e observando as limitações do DF.

Consultou-se o documento de informações gerais sobre o espaço rural do DF disponibilizado pela Empresa de Assistência Técnica e Extensão Rural - EMATER (2013), para verificar á área dos imóveis rurais existentes no DF. Sendo também consultado o Boletim Informativo do Ministério do Meio ambiente, publicado em 30 de Abril de 2015 que sofreu atualização em 2 de Maio de 2015, e estabelece o quantitativo dos imóveis rurais cadastrados.

Diante das legislações pertinentes realizou-se um diagnóstico descrevendo alguns obstáculos que o DF enfrenta com a implementação do CAR. No desenvolvimento desta análise houve consultas a dados secundários juntos a atores envolvidos no processo, tais como Ministério do Meio Ambiente (MMA), Instituto Brasília Ambiental (IBRAM) e EMATER. Também houve aplicação de questionário junto aos detentores de imóveis rurais como o intuito de visualizar se obteve alguma dificuldade na realização do cadastro.

A aplicação dos questionários deu-se durante a realização da Feira Internacional dos Cerrados AgroBrasília, sendo situada às margens da BR 251 entre os dias 12/05 à 16/05. Ao todo foram aplicados 50 questionários. Os entrevistados residiam nos estados de Goiás, Minas Gerais, Bahia e DF.

\section{RESULTADOS E DISCUSSÕES}

\subsection{Quantitativo de propriedades rurais cadastradas no CAR até o mês de maio de 2015.}

Conforme apresentado na Figura 1, no âmbito do DF, os imóveis rurais estão distribuídos em diversas Regiões Administrativas. Porém, observa-se uma maior concentração destes nas regiões do Paranoá, São Sebastião e Planaltina. 

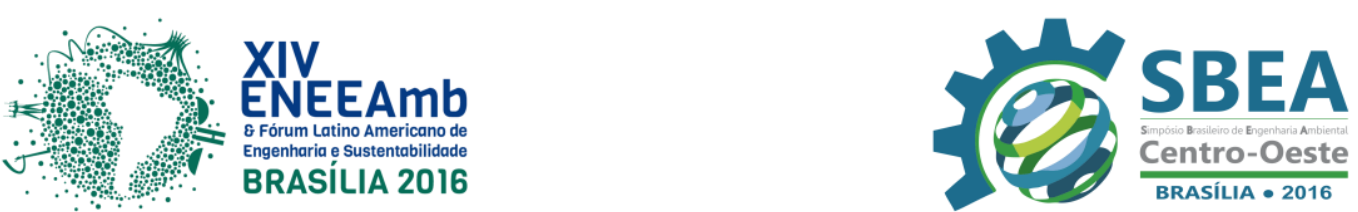

Figura 1: Demonstrativo das propriedades rurais nas Regiões Administrativas do DF

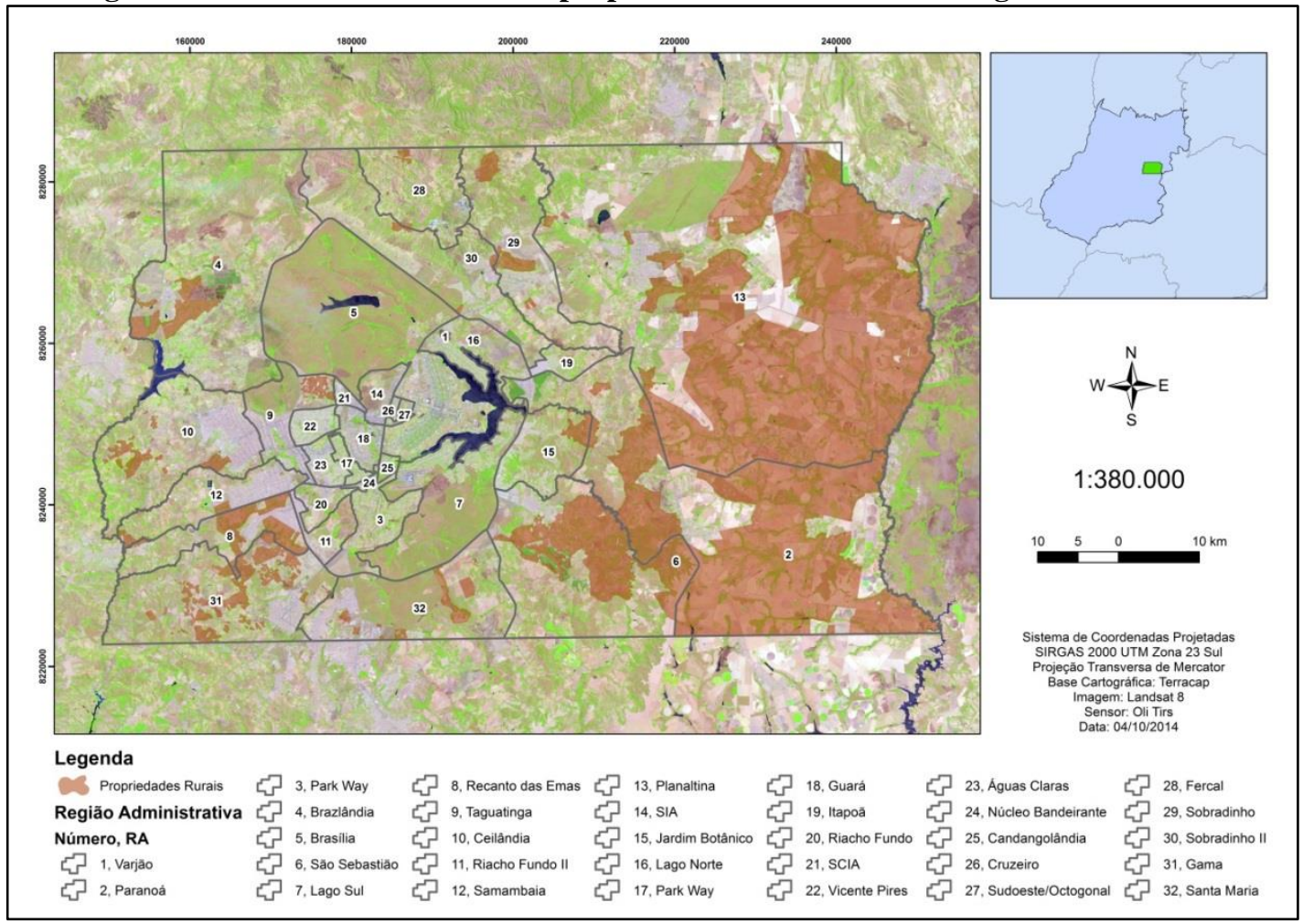

De acordo com a EMATER (2013) no Distrito Federal existem 18.309 propriedades rurais. Destas, $15.807(86,33 \%)$ são pequenas propriedades (abaixo de 4 módulos fiscais). Sendo que a maior parte de propriedades rurais no DF se enquadra abaixo de 20 hectares.

Conforme a publicação do Ministério do Meio Ambiente, até 2 de Maio de 2015, haviam 1.222 propriedades já cadastradas no DF, o que corresponde a 6,67\%, valor muito inferior quando consideramos o montante total (MMA, 2015).

\subsection{Diagnóstico dos obstáculos do DF na implementação da ferramenta.}

Diante da obrigatoriedade do CAR, no âmbito do Sistema Nacional do Cadastro Ambiental Rural (SICAR), foi criada uma plataforma que integrará as informações de todo o Brasil de maneira uniforme. No entanto, há de se considerar que, os estados podem ter sua própria plataforma desde que integrem e disponibilize para a consulta no SICAR, conforme estabelecido no Decreto Federal $n^{\circ} 7.830 / 2012$. Assim, os estados podem fazer uma adaptação na plataforma para atender as necessidades contidas na região.

No DF, tem-se observado alguns obstáculos na utilização da plataforma, pois o módulo de cadastro do SICAR apresenta limitações como o fato das imagens fornecidas não serem compatíveis com as áreas legalmente protegidas da região.

As imagens fornecidas pela plataforma são do satélite RapidEye de 2011 que passaram por ortorretificação e possuem resolução espacial de 5 metros (CABRAL, 2013) sendo insuficientes para detalhar a área de propriedades pequenas que equivale a $86,33 \%$ (EMATER, 2013) dos cadastráveis no DF.

Umas das opções que solucionaria as limitações de imagem referência disponibilizado no SICAR, séria o emprego do mapeamento aerofotogramétrico 2013 ou 2014, com resolução espacial mínima de $30 \mathrm{~cm}$ (DISTRITO FEDERAL, 2012), o produto 

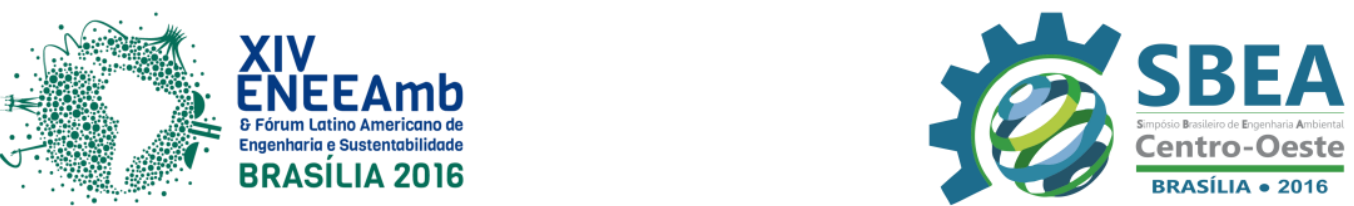

pode ser consultado em WMS (Web Map Service), pelo endereço http://ortofoto.mapa.codeplan.df.gov.br/mapcache. Conforme a Figura 2 comparativa.

Figura 2: Imagem comparativa do SICAR, GOOGLE e TERRACAP
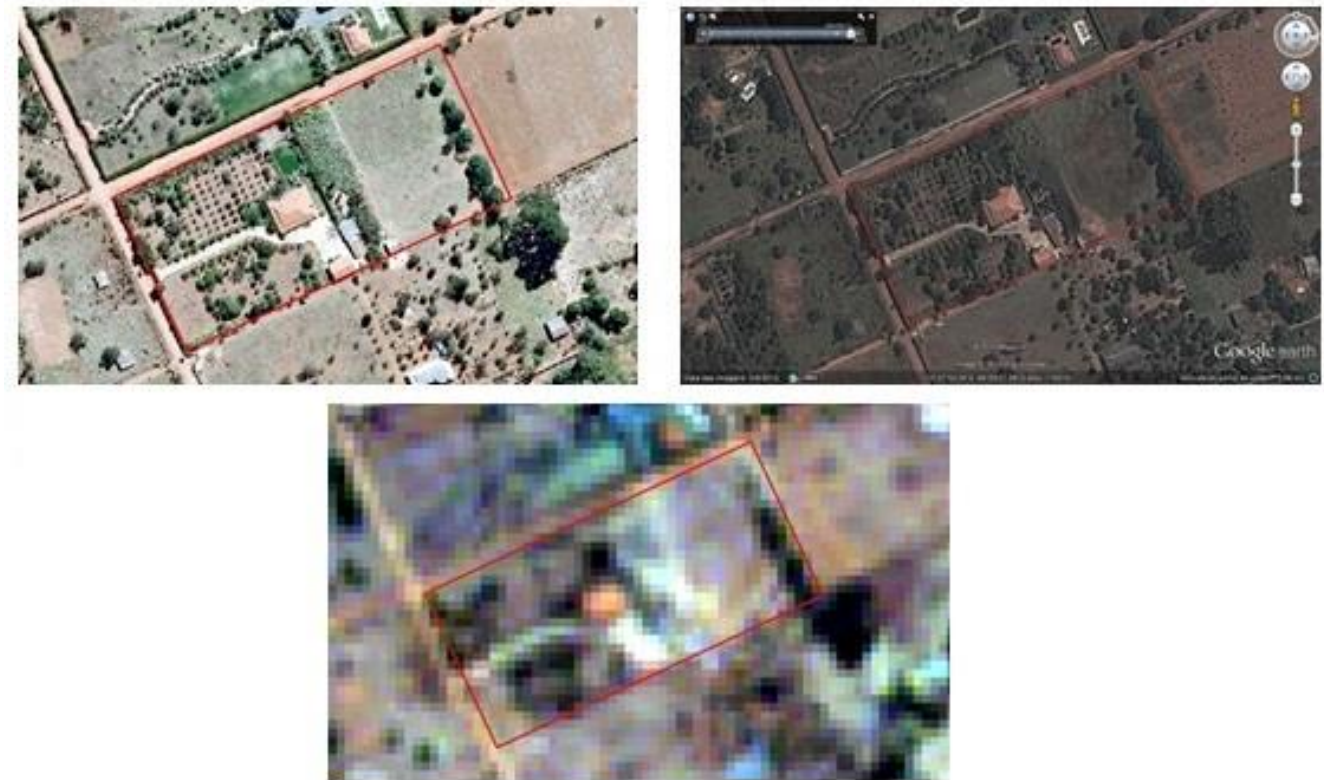

O Módulo de Cadastro do SICAR contém diversas áreas protegidas descritas no Código Florestal, mas as mais comuns no DF são: reserva legal, área de uso restrito, APP de curso d'água, nascentes, veredas, declividade e campo de murundu, além de canal natural de escoamento superficial. Entre essa diversidade, a plataforma não tem função específica para edição de campos de murundus e canal natural de escoamento superficial, conforme estabelecido na IN 39 do IBRAM e no Decreto 30.315 da Câmara Legislativa do DF.

Foram aplicados questionários na Feira Internacional dos Cerrados em busca de avaliar se os produtores rurais já ouviram falar no CAR, se já realizaram o cadastramento do seu imóvel, de identificar a dificuldade no processo de cadastramento, se contratou um profissional para realizar o cadastro e se recebeu alguma assistência do poder público. Porém, devido à diversidade do público que participou da feira os entrevistados não são do Distrito Federal como o esperado, mas ainda sim é um indicativo e obtive respostas.

Dos questionários aplicados observa-se que grande parte do público já ouviu falar no Cadastro Ambiental Rural, mas menos da metade realizaram o cadastro da sua propriedade, conforme a Figura 3.

Figura 3: Resultado de conhecimento do CAR
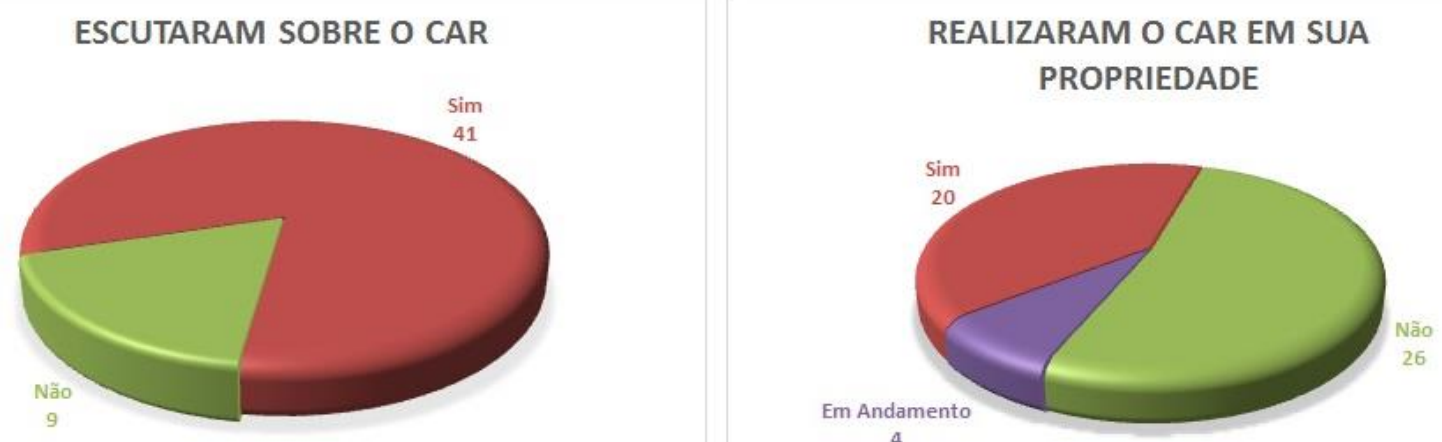

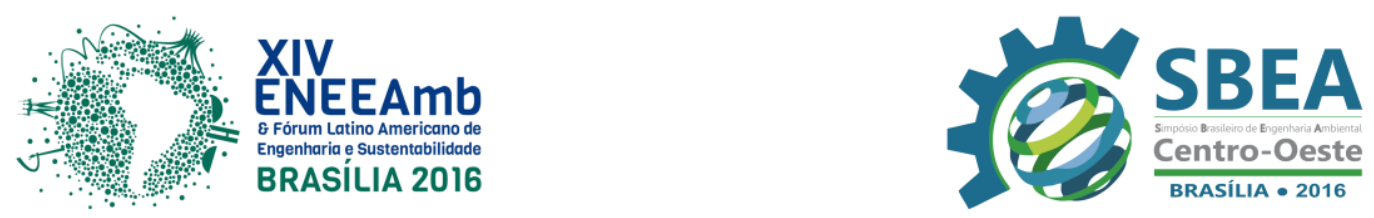

Com a aplicação dos questionários, ficou evidente que a grande parte dos proprietários não realizou o seu cadastro por falta de informação e até mesmo pelo prazo da realização do cadastro ter sido prorrogado.

Do total de 24 pessoas que realizaram o cadastramento, 15 afirmaram ter pouca dificuldade devido à contratação de profissionais especializados na área, já os que não efetuaram nenhum tipo de contratação profissional, já trabalhavam na área ou tiveram dificuldade na etapa "Aba Geo", na qual deve-se georreferenciar a área de interesse, conforme apresentado na Figura 4.

Nota-se também que mais da metade não recebeu assistência técnica do poder público, dizendo que as informações passadas são insuficientes para realizar o cadastramento. Porém os que receberam assistência ficaram satisfeitos, conforme Figura 5.

Figura 4: Pessoas que contrataram especialistas na área

\section{CONTRATARAM ESPECIALISTAS NA ÁREA}

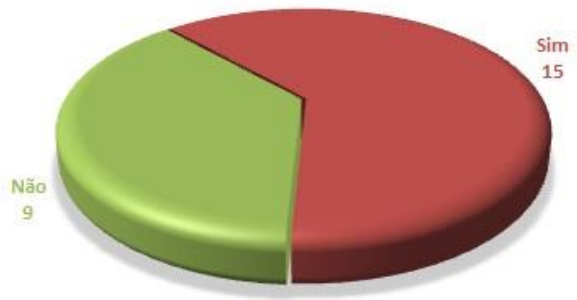

Figura 5: Pessoas que receberam assistência ou auxilio ou informação técnica INFORMAÇÃO TÉCNICA

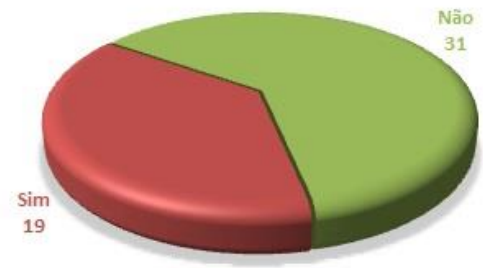

\section{CONSIDERAÇÕES FINAIS}

O Cadastro Ambiental Rural se fez obrigatório somente na publicação do Novo Código Florestal (Lei 12.651/12), mas nessa publicação não relata as diretrizes necessárias para a implementação do cadastramento. O que contribuiu para a publicação de diversas instruções normativas e decretos para preencher as lacunas e aperfeiçoar a ferramenta.

Observa-se que o quantitativo de propriedades rurais já cadastradas é bem inferior ao valor total das propriedades existentes no DF. Podendo considerar uma falha na divulgação, na ação e até mesmo capacitação dos órgãos competentes do CAR. Ao longo dos questionários aplicados pude conversar com diversos proprietários e muitos relataram que não tiveram informação suficiente e que nem o órgão competente conseguia esclarecer as dúvidas. Por esse motivo que os imóveis cadastrados foram inferiores com o que era esperado.

Dentre os obstáculos da implementação do CAR a plataforma é um dos mais importantes, pois não atende as necessidades da região em dois aspectos. A resolução da imagem não é compatível com o tamanho das propriedades, pois a resolução é baixa o que dificulta a visualização de propriedades abaixo de 4 módulos fiscais que equivale a maior parte de imóveis rurais no DF. Outro fator é a plataforma não atender a necessidade de áreas protegidas existentes na região. A plataforma SICAR é nacional e atende as legislações federais, sendo que campo de murundu e canal natural de escoamento superficial não se enquadra em área protegida conforme estas legislações, mas de acordo com as legislações distritais é uma área protegida. 

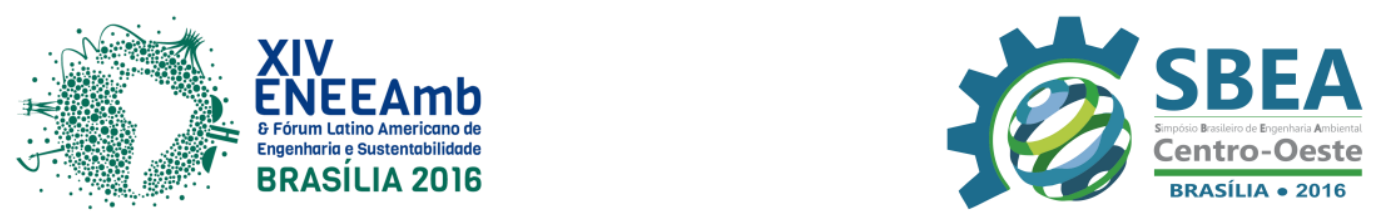

\section{Agradecimentos}

A Deus por ter me ajudado até aqui, proporcionando força e fé para concluir mais uma etapa na minha vida. A orientadora Tatyane, co-orientadora Janaína e o Alisson Neves por toda paciência, serenidade, compreensão, conselhos, sugestões, orientações e inúmeras correções que realizaram. A todos da Gerencia de Reserva Legal do IBRAM que me acolheram e se colocaram a disposição de esclarecer qualquer dúvida existente sobre o Cadastro Ambiental Rural. Agradeço também a todos os amigos que me ajudaram na construção do trabalho e aqueles que me ouviram durante horas, que me incentivaram, apoiaram, acreditaram, aconselharam e por toda paciência e carinho durante essa minha jornada universitária. Cada um foi peça fundamental para a conclusão desse trabalho e sou muito grata a cada uma de vocês.

\section{REFERÊNCIAS E CITAÇÕES}

BRASIL, Código Florestal de 2012. Brasília, DF, 2012. <http://www.planalto.gov.br/ccivil_03/_Ato2011-2014/2012/Lei/L12651.htm>. Acesso em: 15 maio 2015.

BRASIL, Decreto $\mathbf{n}^{\mathbf{8}}$ 8.235. Brasília, DF, 2014. Disponível em < http://www.planalto.gov.br/CCIVIL_03/_Ato2011-2014/2014/Decreto/D8235.htm>. Acesso em: 15 maio 2015.

BRASIL, Decreto $\mathbf{n}^{\mathbf{0}}$ 7.830. Brasília, DF, 2012. Disponível em: < http://www.planalto.gov.br/CCIVIL_03/_Ato2011-2014/2012/Decreto/D7830.htm>. Acesso em: 15 maio 2015.

BRASIL, Decreto $\mathbf{n}^{\mathbf{0}}$ 30.315. Brasília, DF, 2009. Disponível em: < https://cidadaoecologicobrasiliense.files.wordpress.com/2011/05/dec-df-30315-2009definic3a7c3a3o-e-disposic3a7c3b5e-para-licenciamento-em-faixa-marginal-deprotec3a7c3a3o-de-cursos-dc3a1gua.pdf>. Acesso em: 31 maio 2015.

CABRAL, Paulo Guilherme. Cadastro Ambiental Rural - CAR A Revolução da Geoinformação chegou ao Campo. 2013. Disponível em: 〈http://mundogeoconnect.com/2013/arquivos/palestras/18_jun-bcd-paulo_guilherme.pdf >. Acesso em: 31 maio 2015.

CURSO dE CAPACITAÇÃO PARA O CADASTRO AMBIENTAL RURAL CAPCAR. Ministrado pela Universidade Federal de Lavras em parceria com o Ministério do Meio Ambiente. Período de 08/12/2014 a 05/02/2015, totalizando 78 horas de carga horária.

CODEPLAN. Disponível em: 〈http://ortofoto.mapa.codeplan.df.gov.br/mapcache>. Acesso em: 31 maio 2015.

DISTRITO FEDERAL. Maria de Fátima Vilela. Empresa Brasileira de Pesquisa Agropecuária. Conservação dos Recursos Naturais. 2014. Disponível em: <http://www.agencia.cnptia.embrapa.br//Agencia16/AG01/arvore//AG01_35_911200585233. $\underline{\mathrm{html}}>$. Acesso em: 31 maio 2015. 

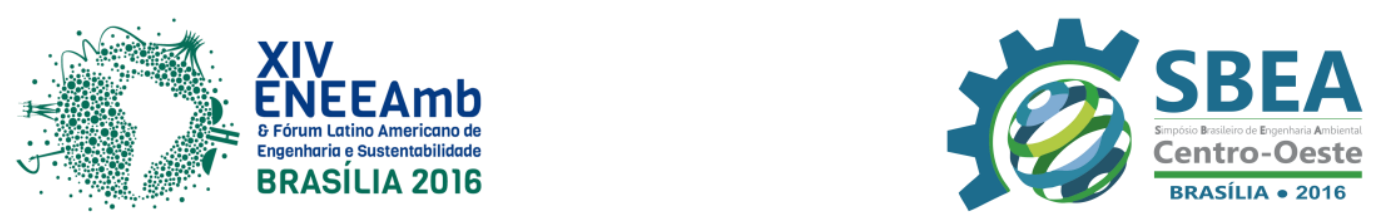

DISTRITO FEDERAL. Instituto Do Meio Ambiente E Dos Recursos Hídricos - IBRAM. Instrução Normativa no 39, de 21 de janeiro de 2014. Dispõe sobre a preservação dos campos de murundus, também conhecidos como covais e dá outras providências. Disponível em: <http://www.ibram.df.gov.br/images/Instrucao Normativa 39 de 21 de Fev 2014.pdf >. Acesso em: 31 maio 2015.

EMPRESA DA ASSISTÊNCIA TÉCNICA E EXTENSÃO RURAL DO DISTRITO FEDERAL - EMATER. Informações Gerais sobre o Espaço Rural do Distrito Federal. 2013.

GALINDO-LEAL, C. (et al.). Estado dos Hotspots: A dinâmica da perda de biodiversidade. In: GALINDO-LEAL, C.; CÂMARA, I. de G. Mata Atântica: biodiversidade, ameaças e perspectivas. São Paulo: Fundação SOS Mata Atlântica - Belo Horizonte: Conservação INTERNACIONAL, 2005, p. 3 a 26. (STATE OF THE HOTSPOTS).

INSTITUTO DE PESQUISA AMBIENTAL DA AMAZÔNIA - IPAM. O que são Serviços Ambientais? É possível compensar economicamente a prestação destes serviços? 2014. Disponível em: <http://www.ipam.org.br/saiba-mais/abc/mudancaspergunta/O-que-saoServicos-Ambientais-possivel-compensareconomicamente-a-prestacao-destes-servicos|40/30>. Acesso em: 20 março 2015.

KLINK, Carlor A.; MACHADO, Ricardo B.; A conservação do Cerrado brasileiro. Mega diversidade, Brasília, v 1, n. 1, p. 144 a 155. Junho 2005.

MINISTÉRIO DO MEIO AMBIENTE - MMA. Instrução Normativa no 2 , de 5 de maio de 2014. Dispõe sobre os procedimentos para a interação, execução e compatibilização do Sistema de Cadastro Ambiental Rural - SICAR e define os procedimentos gerais do Cadastro Ambiental Rural - CAR. Disponível em: < http://pesquisa.in.gov.br/imprensa/jsp/visualiza/index.jsp?.jornal=1\&pagina=59\&data=06/05/2 014>. Acesso em: 15 maio 2015.

MINISTÉRIO DO MEIO AMBIENTE - MMA e SERVIÇO FLORESTAL BRASILEIRO. Boletim Informativo. Brasília, DF, 2015. Disponível em: < http://www.florestal.gov.br/noticias-do-sfb/imagens-do-mural/balanco-do-cadastroambiental-rural-car>. Acesso em: 31 maio 2015.

SILVA, J.A.A. O código florestal e a ciência: contribuições para o diálogo. ISBN 978-858695-16-1, São Paulo: Sociedade Brasileira para o Progresso da Ciência, SBPC: Academia Brasileira de Ciência, ABC, 2011, p. 124. 